\begin{tabular}{|l|l|l||}
\hline \multicolumn{2}{|c|}{ PublisherInfo } \\
\hline \hline PublisherName & $:$ & BioMed Central \\
\hline \hline PublisherLocation & $:$ & London \\
\hline \hline PublisherImprintName & $:$ & BioMed Central \\
\hline \hline
\end{tabular}

\title{
Mimics in Listeria
}

\begin{tabular}{|l|l|l||}
\hline \multicolumn{2}{|c|}{ ArticleInfo } \\
\hline \hline ArticleID & $:$ & 4330 \\
\hline \hline ArticleDOI & $:$ & $10.1186 /$ gb-2002-3-4-reports0019 \\
\hline \hline ArticleCitationID & $:$ & reports0019 \\
\hline \hline ArticleSequenceNumber & $:$ & 20 \\
\hline \hline ArticleCategory & $:$ & Paper report \\
\hline ArticleFirstPage & $:$ & 1 \\
\hline \hline ArticleLastPage & $:$ & 4 \\
\hline \hline & & RegistrationDate : 2002-1-21 \\
ArticleHistory & $:$ & Received \\
\hline \hline ArticleCopyright & $:$ & BioMed Central Ltd2002 \\
\hline \hline ArticleGrants & $:$ & \\
\hline \hline
\end{tabular}




\begin{tabular}{|l|l|l||}
\hline ArticleContext & $:$ & 130593344 \\
\hline
\end{tabular}

\section{Wim D'Haeze}

\section{Abstract}

A Listeria monocytogenes glucose-6-phosphate translocase shows how parasitic bacteria can use molecular mimicry to survive within eukaryotic host cells

\section{Significance and context}

The bacterium Listeria monocytogenes is a food-borne facultative intracellular parasite responsible for the disease listeriosis, which can be fatal. The symptoms are septicemia, brain infection and miscarriage; newborn babies, pregnant women and the elderly are most at risk of infection. Because several hundred cases are reported each year in industrialized countries, L. monocytogenes infection is considered a public health and economic problem and is an important subject of research.

Once taken up into a host cell by phagocytosis, L. monocytogenes escapes from the phagocytic vacuole and replicates in the cytosol. Escape from the vacuole involves production of a pore-forming toxin, listeriolysin $\mathrm{O}$, and two phospholipases $\mathrm{C}$ encoded by the genes $p l c A$ and $p l c B$. After rapid proliferation in the cytosol, the bacterium spreads directly to neighboring cells by a mechanism of actinbased motility. This is dependent on the induced production of host-cell actin by Listeria polymerizing enzyme, ActA. The pathogenicity of L. monocytogenes depends on the expression of a set of genes organized in a regulon (a set of coordinately regulated but not necessarily adjacent genes), which is controlled by the transcriptional activator PrfA. By searching for physiological functions regulated by PrfA, Chico-Calero et al. have now isolated and characterized a L. monocytogenes gene encoding a glucose-6-phosphate translocase which is required for the efficient survival of the bacterium within the eukaryotic host cell.

\section{Key results}

It has been observed that, in contrast to non-pathogenic species, a variety of pathogenic Listeria species, including L. monocytogenes, utilize glucose-1-phosphate in a PrfA-dependent way. $L$. monocytogenes can also use glucose-, fructose-, and mannose-6-phosphate efficiently. The genome sequence was screened for genes preceded by a PrfA-binding site (the PrfA box) and so likely to be involved in pathogenicity. Out of nine sequences found, the inferred protein product of one showed significant similarity to a hexose-phosphate permease found in enteric bacteria, and was named the 
hexose-phosphate transporter (Hpt). Hpt was also found to be similar to the translocase component of a mammalian glucose-6-phosphatase enzyme complex. This is involved in the transport of glucose-6-phosphate from the cytosol to the lumen of the endoplasmic reticulum, suggesting that Hpt in L. monocytogenes might mediate the import of glucose-6-phosphate, and related sugars, from the cytoplasm of the infected cell into the bacterium. These sugars could then be used as carbon and/or energy sources for bacterial survival and rapid replication within the host cell. A mutation in hpt had no influence on bacterial growth in broth, but it did severely affect the ability to utilize glucose-1-phosphate, and glucose-, fructose- and mannose-6-phosphate. L. monocytogenes hpt mutants also showed impaired growth in a variety of mammalian cell types. The impairment was not caused by decreased production of listeriolysin $\mathrm{O}$ or decreased expression of $p l c A$ and $p l c B$, nor by a delay in phagosomal escape. These observations suggested that Hpt-mediated utilization of hexose phosphates is required for efficient rapid replication in the cytosol of the infected cell. This was confirmed by following the kinetics of L. monocytogenes wild-type and hpt mutant bacteria within mouse spleen and liver cells.

\section{Links}

The complete genome sequences of L. monocytogenes and L. innocua are available at the TIGR Microbial Database.

\section{Conclusions}

The authors draw two interesting conclusions. First, the presence in the bacterium of a mammaliantype glucose-6-phosphate translocase and its involvement in the movement of sugars from the cytosol into the bacterium suggest an example of adaptation to a parasitic life style by mimicry of eukaryotic cell functions. This may provide us with new insights into how bacteria evolve into intracellular parasites. Second, the authors note that drugs that specifically abolish the function of bacterial glucose-6-phosphate translocases might be a new therapeutic lead to treating infected patients.

\section{Reporter's comments}

This work contributes significantly to our understanding of how L. monocytogenes survives inside eukaryotic cells. Improved understanding could provide the basis for developing drugs that arrest infection and cure the disease. In-depth research on Hpt might indeed lead to drugs that specifically inhibit bacterial, but not eukaryotic, hexose-phosphate transporters. One can, however, question how rapidly and efficiently such drugs would be taken up by parasites already inside the host cells. As expression of the hpt gene is tightly controlled by the transcriptional activator PrfA, which controls a 
whole set of genes required for intracellular parasitic life, it could also be useful to develop drugs that inactivate PrfA. Such drugs might be even more effective than ones targeted on Hpt, as they will inactivate a whole set of processes that mediate bacterial infection and survival within host cells.

\section{Table of links}

Proceedings of the National Academy of Sciences of the United States of America

TIGR Microbial Database

\section{References}

1. Chico-Calero I, Suárez M, González-Zorn B, Scortti M, Slaghuis J, Goebel W, The European Listeria Genome Consortium, Vázquez-Boland JA: Hpt, a bacterial homolog of the microsomal glucose-6-phosphate translocase, mediates rapid intracellular proliferation in Listeria. Proc Natl Acad Sci USA. 2002, 99: 431-436. 0027-8424

This PDF file was created after publication. 